\title{
Passenger Experience of China's High Speed Rail (HSR) Service
}

\author{
Ruining Wu \\ Yantai Nanshan University, Yantai, China \\ Email: wuruining123@hotmail.com
}

How to cite this paper: Wu, R.N. (2018) Passenger Experience of China's High Speed Rail (HSR) Service. Open Journal of Social Sciences, 6, 253-259.

https://doi.org/10.4236/jss.2018.63018

Received: February 14, 2018

Accepted: March 27, 2018

Published: March 30, 2018

Copyright $\odot 2018$ by author and Scientific Research Publishing Inc. This work is licensed under the Creative Commons Attribution International License (CC BY 4.0).

http://creativecommons.org/licenses/by/4.0/

\begin{abstract}
The development of high-speed rail (HSR) is one of the high priority programs in China. China's HSR network has become the most heavily used transportation system in the world. Despite its advanced technical features, however, little research focuses on passenger experience and passenger interaction with HSR system; passengers' satisfaction of high-speed train service is relatively low in China. This article identifies four factors influencing passenger experience in China's high-speed train station, namely 1) the price, 2) the people present, 3) the service process and 4) the physical facilities. By this article, we would learn the new knowledge about passenger experience of Chinese HSR train station. These new insights can also be used to optimize passengers' experience of China's high-speed train station design.
\end{abstract}

\section{Keywords}

High-Speed Rail (HSR), Passenger Experience, Passenger’s Satisfaction

\section{Introduction}

High-speed railway (HSR) is regarded as one of the most significant technological breakthroughs in passenger transportation developed in the second half of the 20th century [1]. More than 15 countries now offer high-speed rail and the network is still expanding rapidly [2]. In China, it has been eight years since the opening of the first high-speed rail line. As an efficient and energy-saving modernization of public transport, it is of great significance for China's economy, environment, and way of life. The system has a number of technologically advanced features-sophisticated reservation systems, online ticketing, on-board IT services, and more. China's HSR system therefore offers a significant improvement over traditional rail transport. 
Despite the advanced technical features, however, little research focuses on the passenger experience and passenger interaction with HSR service; passenger's satisfaction with the HSR service particularly with the train station service is in fact relatively low. Several passenger satisfaction surveys for China's HSR have highlighted that passengers are generally less than satisfied with the HSR stations in China [3].

There are passenger experience problems in a number of train station areas, such as ticketing service, lack of station staff and insufficient waiting facilities. Focusing on passenger experience of China's high-speed rail service in the train station will help to improve these problems. Several researchers have emphasized the importance of the passenger experience. Norman (1986) popularized the term "user-centered" to describe design based on the needs of the user. He says that user-centered design is the key to a successful product or service [4]. Similarly, Garret (2010) published a model supporting the idea that the user comes first and the users' needs create the foundation for a product [5]. All researches described above support the idea of "user-centered design" and emphasize the importance of accurately defining user requirements to improve a given product or service. Therefore, the HSR service should center not on technology developments, but instead on the experiences of people [6].

\section{The Development of High-Speed Rail Service}

\subsection{The Develop Background of High-Speed Rail (HSR) Service in China}

Before China's economic reform in the 1980s, the Japanese government advised Deng Xiaoping (China's leader from 1978 to 1992) that a direct way to develop economy is to invest in infrastructure and transportation. Since then, the Chinese government has invested extensively in the railway service system [7].

After the high-speed railway construction plan was announced in 2004, the first Chinese-made high-speed train (CRH380) was launched in April 2007 from Beijing to Shanghai at the speed of $380 \mathrm{~km} / \mathrm{h}$, reducing the travel time from 10 hours to 5 hours. Since the initial journey of an HSR train in China, annual ridership has risen from 61.21 million in 2007 to 420 million in 2011, making China's HSR service the most heavily used in the HSR service market.

The development of HSR contributes to alleviating China's Chunyun (spring festival travel) problems. When the Lunar New Year comes, all the migrants are going back home and celebrate the New Year with their families, as a result, the travel demand become larger and most people face the problem to buying railway tickets, a large number of people had to queue in line in the train station for the tickets which bring serious congestion problem in the train station [8]. Furthermore, in contrast with the traditional rail and airline, HSR offer more ways for passengers to purchase tickets, such as purchasing from the ticketing window, or from self-vending machine, through online, mobile, and phone call [8].

The HSR service also plays an important role in promoting China's domestic 
tourism. Considering the time, price and accessibility, an increasing number of people choose HSR service to travel. It is estimated that the HSR service network in China will cover $90 \%$ of the population in China by 2020 [9]. The HSR service network has had some major effects on the cumulative movement of passengers in China, and is now influencing every aspect of people's lives.

First, the present operational speed of the HSR greatly shortens journey time and perceived distance between cities, promoting the concepts of "one-hour life circle" and "half-hour life circle" development in China. The ideas of a "one-hour life circle" and "half-hour life circle" arose from China's fast transportation system; it means that people can travel to a new city in just an hour or half an hour and expand upon their life experiences. Having access to a "one-hour life circle" or "half hour circle" enables people to experience a variety of cultural activities supplied by different cities. For example, one can eat the traditional spicy soup of the Henan Province for breakfast, and then travel to the famous Shaolin monastery in Dengfeng County that same afternoon. This type of inter-city travel will become more and more popular in Chinese life [10].

Second, because of the convenience and reasonable ticket prices of high-speed rail, it attracts many people who have never traveled before. Although the ticket prices of HSR trains are slightly higher than an ordinary train, it is still much cheaper than airfare. Take the Beijing to Shanghai HSR line, for instance: a soft sleeper on an ordinary train is CNY 476.5, a second class of HSR train is CNY 553 , yet the full fare of an economy class plane ticket is over CNY 1000. In comparison with the traditional train and an airplane, the HSR service is more cost effective.

HSR also offer other convenience for users, for example, it has a more reliable schedule, and many stations can be accessed by subway or public bus, making the train journey more convenient than ever before. In addition to the accessibility advantage, HSR offers a variety of technological innovations. For example, the Intelligent Client Service System provides passengers with the train timetables, ticket prices, and train operation information on both desktop and mobile interfaces. Understanding these technological innovations is important as it plays an important role in improving the passenger experience. The Intelligent Train Control and Dispatching System aims to increase the speed and density of train traffic for the most efficient utilization of the rail system. The Intelligent Emergency Rescue and Safety Supervision System are designed to guarantee the security of the high-speed rail system [11].

Despite the advanced technical features mentioned in the above section, however, little research focuses on passenger experience and passenger interaction with HSR services. Passenger satisfaction with the high-speed rail service is relatively low and majority of station areas are still problematic which need to be improved.

\subsection{The Emerging Problems of High-Speed Rail Service in China}

The main passenger experience problems in China's HSR train stations are: 1) 
ticketing system; 2) lack of station staff; 3) insufficient waiting facilities in the train station.

The first problem is ticketing system, although online ticketing is intended to make it easier for passengers to buy and exchange tickets, the system still faces a number of challenges. Increased travel demand during holidays like the national festival and Chinese New Year, for example, overload the system and make it very difficult for customers to get a ticket. In addition, many are simply not accustomed to the online ticketing service and will still choose to wait in line to purchase a ticket in the station. This creates additional inconveniences for the elderly hoping to use the HSR service, who often find it difficult to queue for extended periods of time due to their health condition.

Furthermore, the ticketing service ignored passengers' need and create inconvenience for passengers, for example, if passengers lose tickets, there is no way for the operators to know whether or not passengers bought the tickets, passengers have to get refund and buy tickets again.

Besides the ticketing system, a lack of station staff inconveniences passengers who face problems understanding the self-ticketing system and timetables. In Beijing South train station, for instance, large numbers of passengers are uncertain whether they have passed the station, they tend to ask for help rather than reading information and signage, this will further cause the congestion problems in the train station.

The last problem of China's high-speed train station is the waiting service. Due to the large numbers of passengers in China, the train stations always designed like the airport terminal, with large spaces, and lengthy transfer times. Because the security check process was conducted before check-in at the China's high-speed train station, therefore, most people gathered at the center waiting area that cause the congestion problem in the train station. Moreover, the insufficient seats in the waiting area, poor facilities for individuals with disabilities or excess luggage and food and restaurant quality in the train station decrease passengers' waiting experience.

These problems in the train station reveal that the high-speed rail industry still faces considerable challenges, and passengers are consistently less satisfied with China's high-speed train station. It is clear that China's HSR service providers should pay great consideration for improving passenger experience.

\section{Passenger Experience of High-Speed Rail (HSR) Service in China}

Passenger experience has becoming an increasingly popular topic in transportation research. Nowadays, there is consensus on the importance of research on passenger experience across all areas of transportation, including public transportation and the rail industry [12]. It is acknowledged that focusing on passenger experience is a way for operators and providers to improve competitiveness and attract more passengers to increase economic benefits. Therefore, under- 
standing passenger experience is not an option; instead, it is a necessity to improving profitability.

Passenger Experience of High-Speed Rail journey is critical, when passenger's journey experience is enjoyable, passengers are likely to be continued their travel over a period of time, and repeated. The journey experience can be influenced by several factors, there is growing understanding of the importance of affective factors in travel satisfaction.

Based on a review of academic literature, four primary components can influence passengers' experience: 1) the price, 2) the people present, 3 ) the service process and 4) the physical facilities.

First, the price is recognized as one of the key competing element for the service providers. A customer's decision about a service or product is commonly based on the identification of the price considered alongside the expected benefits. China's high speed train tickets including six different types: 1) second class seat, 2) first class seat, 3) business class seat, 4) VIP seat, 5) soft sleeper, and 6) luxury soft sleeper. The ticket price for each type is different, and the ticket price is designed for different people. Second class seat is the most popular type among these class seats, the ticket price is the lowest of all others on high speed trains. The space on the second class is like the economy class on the airplane, with chair being about 17 inches $(42 \mathrm{~cm})$ wide and the leg room 16 inches (40 $\mathrm{cm}$ ) between two rows. The business class seat is expensive but more comfortable, similar to the business class on an airplane. Soft sleeper and luxury soft sleepers are only available on the overnight bullet trains; they are good choices for an overnight journey [13].

Second, a customer's level of satisfaction can change based on the presence of people. For example, too many people can result in negative feelings. In China, crowding and congestion are big problems in the train station environment (Figure 1). The high level of passenger density leads to critical safety. Jiang et.al (2009) studied passenger flow at the platform staircase of a subway station in a big Chinese city to understand crowding conditions. They point out that there is a peak flow during peak morning hours [14]. The crowding of train stations might bring a lot of inconveniences for many passengers. For example, during major national holidays and festivals, getting a railway ticket and making a trip are a major endeavor for travelers. This crowded environment will cause anxiety for many passengers and will contribute to the avoidance behavior. For example, passengers may want to leave, and avoid an area that they do not feel comfortable in, like an unpleasant and noisy place.

Third, the service process can also influence customer satisfaction. A customer's satisfaction will be relatively high when the service operates efficiently and smoothly. Station crowding may block passengers from entering and existing the train station quickly and safely, for example, if passengers' volume are so high, then passengers flow in the train station will be significantly obstructed, this will reduce the average process speeds in the train station. The congestion will take 


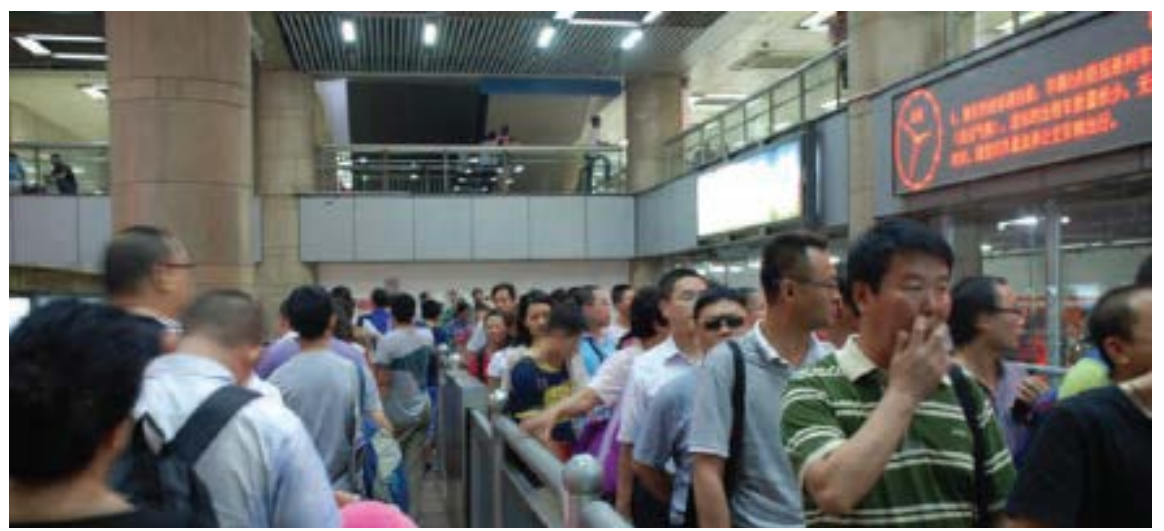

Figure 1. Beijing South train station.

place in a number of areas, such as the stairways, escalators and waiting area. In these train station environment, people have to wait to complete the boarding process, accordingly, waiting time plays an important part of passengers' train journey. Longer waiting times may cause passengers' dissatisfaction with the service. They may feel uncomfortable, uncertain, frustrated, stressed or even frightened. The adverse effects of the waiting time on passenger satisfaction at train stations may be alleviated by providing a pleasant environment, information, activities and other forms of distraction instead of shortening the objective waiting time.

Last but not least, the physical facilities, or the service environment, can positively or negatively influence customers' experience. If the environment is comfortable, clean, safe, and offers usable products, then the consumer will have greater confidence in the quality of the service provider. Technologies facilities such as mobile devices, social media and the proliferation of wireless networks and virtual systems have also changed passengers' behavior and passenger experience. With the development of mobile platforms, more and more applications work on mobile devices. For example, people might use their mobile phone to find a special place for dinner, obtain movie tickets or find the detailed maps of the train station.

\section{Conclusions}

Recently, high-speed railway construction in China has made astonishing achievements; China's independent research and development capability has been greatly improved. As an efficient and energy-saving modernization of public transport, the HSR service is of great significance for China's economy, environment, and way of life. While for many years, the development of high-speed rail in China has been technology-oriented, rather than focusing on passenger experience, passenger satisfaction with the high-speed rail service is relatively low and there is much room for improvement. Currently, the analysis and research of passenger experience of China's high-speed train is very scarce. This research focuses on passenger experience research of China's high-speed train. 
and identifies four factors influencing passenger experience in China's high-speed train station, namely 1) the price, 2) the people present, 3) the service process and 4) the physical facilities.

By this article, one would learn the new knowledge about passenger experience of Chinese HSR service, which is a totally blank area in current HSR service researches. This research will significantly contribute to benefiting the administrating efficiency and passenger experience for Chinese HSR service.

\section{References}

[1] Campos, J. and De Rus, G. (2009) Some Stylized Facts about High-Speed Rail: A Review of HSR Experiences around the World. Transport Policy, 16, 19-28. https://doi.org/10.1016/j.tranpol.2009.02.008

[2] Thompson, L.S. and Tanaka, Y. (2011) High Speed Rail Passenger Services: World Experience and U.S. Application. Transport Concepts. http://www.tgaassoc.com/documents/final-version-hsr-corrected-9-20-11.pdf

[3] Chen, C.-L., Hickman, R. and Saxena, S. (2014) Improving Interchanges: Toward Better Multimodal Railway Hubs in the People's Republic of China.

[4] Norman, D.A. and Draper, S.W. (1986) User Centered System Design: New Perspectives on Human-Computer Interaction. Lawerence Erlbaum Associates, Hillsdale, New Jersey.

[5] Garrett, J.J. (2010) The Elements of User Experience. New Riders, San Francisco.

[6] Ciolfi, L. (2007) Supporting Affective Experiences of Place through Interaction Design. CoDesign, 3, 183-198. https://doi.org/10.1080/15710880701309308

[7] Chuang, M.Y. and Johnson, W.H.A. (2011) "Hop on Board": The Importation and Future Development of High-Speed Rail (HSR) in Chinanull. Journal of Technology Management in China, 6, 232-241. https://doi.org/10.1108/17468771111157445

[8] Yu, W., Menz, N.M., Hunter, C., Chen, Y.Y. and Farias, P. (2013) An Analysis of the Chinese High-Speed Rail from the American Perspective. Academic Journal, 5, 623.

[9] Cao, J., Liu, X.C., Wang, Y. and Li, Q. (2013) Accessibility Impacts of China's High-Speed Rail Network. Journal of Transport Geography, 28, 12-21. https://doi.org/10.1016/j.jtrangeo.2012.10.008

[10] Channel, C.C.I. (2011) Ignite Spark of the Culture: Economic and Culture Industry of High Speed Rail. http://www.ce.cn/culture/zt/gtjj/

[11] Ning, B., Tang, T., Gao, Z., Yan, F., Wang, F. and Zeng, D. (2006) Intelligent Railway Systems in China. IEEE Intelligent Systems, 21, 80-83. https://doi.org/10.1109/MIS.2006.99

[12] CCD. (2013) What Is "Passenger Experience". http://www.designbyccd.com/thinking/what-is-passenger-experience/

[13] Travel, C. (2008) China High Speed Train (Bullet Train). http://www.travelchinaguide.com/china-trains/high-speed/

[14] Jiang, C.S., Deng, Y.F., Hu, C., Ding, H. and Chow, W.K. (2009) Crowding in Platform Staircases of a Subway Station in China during Rush Hours. Safety Science, 47, 931-938. https://doi.org/10.1016/j.ssci.2008.10.003 